\title{
DC-DC Flyback Converters in the Critical Conduction Mode:
}

\section{a Re-examination}

\author{
G. Spiazzi* D. Tagliavia** S. Spampinato** \\ *Department of Electronics and Informatics \\ University of Padova \\ via Gradenigo 6/a - 35131 Padova - Italy \\ Phone: +39-049-827.7525 Fax: +39-049-827.7699 \\ e-mail: spiazzi@dei.unipd.it \\ *** Microelectronics \\ Via Stradale Primosole 50, 95121 Catania - ITALY \\ Phone: +39-095-740-1111 - Fax: +39-095-740-6006 \\ e-mail: donato.tagliavia@st.com \\ e-mail: sergio.spampinato@st.com
}

\begin{abstract}
The critical conduction mode for DC-DC flyback SMPS, in which the converter is forced to operate at the boundary between continuous and discontinuous conduction modes, represents an interesting alternative to the classical constant-frequency PWM technique. In fact, such operating mode allows for a soft turn off of the freewheeling diode, Zero Voltage commutations of the switch and reduction of the generated EMI.

In this paper, this operating mode is re-examined with the aim of accurately predict switching frequency variation and component stresses in those applications in which the delay inserted between the turn off of the freewheeling diode and the turn on of the switch, used to achieve zero voltage commutations, cannot be neglected. The analysis presented allows for a correct prediction of the converter behavior in all operating conditions as well as for a proper design of the feedback loop through a suitable small-signal characterization.

The theoretical forecasts are verified by means of a flyback prototype built using a new smartpower IC developed by ST Microelectronics in VIPower ${ }^{\circledR}$ M3 technology.
\end{abstract}

\section{INTRODUCTION}

Standard DC-DC converters (buck, boost or buck-boost) in the critical conduction mode, i.e. at the boundary between continuous and discontinuous conduction modes (CCMDCM), have the following advantages as compared to normal constant-frequency PWM operation: soft turn-off of the freewheeling diode (like constant-frequency DCM operation but at a reduced current stress), self-protection capability against short circuit conditions at the output, and reduced turn on and turn off losses by exploiting the resonance between the inductance and the switch output capacitance. This feature is particularly appealing for off-line flyback power supplies in which the high switch voltage stress increases both switching losses and EMI.

Analysis of flyback converters in the critical conduction mode has already been reported in literature [1], but it is usually done neglecting the resonant intervals that occur at the beginning and at the end of each switching interval. This simplification leads to substantial errors in the prediction of the switching frequency variation and of the component stresses in converters designed with a low resonance frequency (for example in order to keep the switch $\mathrm{dv} / \mathrm{dt}$ at turn off below a specified limit).

In this paper, a detailed analysis is reported which allows for an accurate prediction of the converter behavior in all operating conditions. Moreover, a small signal model is

a)

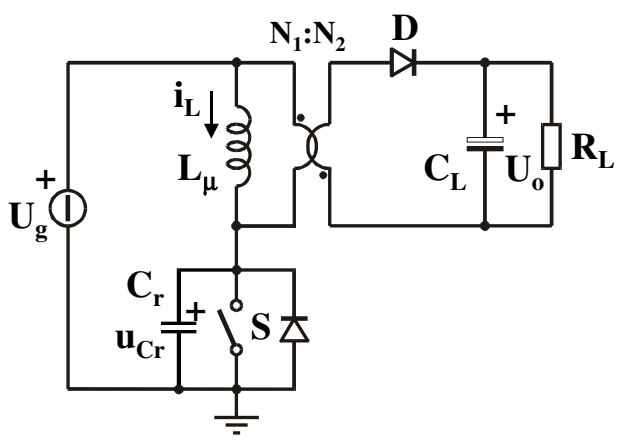

b)

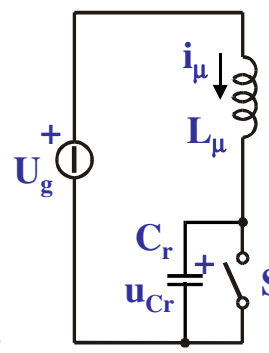

c)

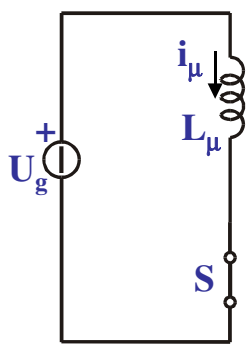

d)

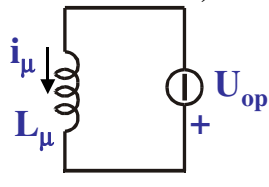

Fig. 1 - a) Basic scheme of a flyback converter in the critica conduction mode; $b$ ) equivalent circuit during subintervals $\mathrm{T}_{\mathrm{d}}$ and $\mathrm{T}_{\text {rise }}$; c) equivalent circuit during $T_{\text {on }}$; d) equivalent circuit during $T_{\text {off }}$ 
developed in order to design properly the feedback loop.

A multioutput flyback prototype employing a new smartpower IC developed by ST Microelectronics in VIPower ${ }^{\circledR}$ M3 technology was built and tested in order to verify the theoretical expectations [2].

\section{REVIEW OF THE CONVERTER OPERATION}

The basic scheme of the flyback converter in the critical conduction mode is shown in Fig. 1a in which the resonant capacitor $\mathrm{C}_{\mathrm{r}}$ accounts for any parasitic capacitance (of the switch, of the freewheeling diode and of the transformer windings) as well as added ones. The circuit operation is very similar to a standard flyback except for the resonant intervals at the beginning and at the end of each switching period. Two different situations can occur depending on the value of the voltage conversion ratio $M=\frac{U_{o p}}{U_{g}}$, where $U_{o p}$ is the output voltage reported to the primary side: when $\mathrm{M}>1$ zero voltage turn on of the switch is achieved as can be seen from the converter main waveforms shown in Fig. 2a, while if $\mathrm{M}<1$ the situation becomes as depicted in Fig. $2 b$. In both cases the switching period $T_{S}=t_{4}-t_{0}$ can be divided in four subintervals which are analyzed in the following, assuming a new time origin at the beginning of each subinterval.

\section{A. Interval $T_{d}=t_{1}-t_{0}$.}

At instant $t_{0}$ the magnetizing current zeroes causing the turn-off of the freewheeling diode D. The equivalent circuit during this subinterval is shown in Fig. 1b: the magnetizing inductance $L_{\mu}$ resonates with capacitor $C_{r}$ bringing its voltage toward zero. The magnetizing current and the capacitor voltage are given by the following equations $\left(\mathrm{u}_{\mathrm{Cr}}(0)=\mathrm{U}_{\mathrm{g}}+\mathrm{U}_{\mathrm{op}}, \mathrm{i}_{\mu}(0)=0\right)$ :

$\mathrm{u}_{\mathrm{Cr}}(\mathrm{t})=\mathrm{U}_{\mathrm{g}}+\mathrm{U}_{\mathrm{op}} \cos \left(\omega_{\mathrm{R}} \mathrm{t}\right)$

$\mathrm{i}_{\mu}(\mathrm{t})=-\frac{\mathrm{U}_{\text {op }}}{\mathrm{Z}_{\mathrm{R}}} \sin \left(\omega_{\mathrm{R}} \mathrm{t}\right)$

where $\omega_{\mathrm{R}}=\frac{1}{\sqrt{\mathrm{L}_{\mu} \mathrm{C}_{\mathrm{r}}}}$ and $\mathrm{Z}_{\mathrm{R}}=\sqrt{\frac{\mathrm{L}_{\mu}}{\mathrm{C}_{\mathrm{r}}}}$ are the angular frequency and the characteristic impedance of the resonant circuit respectively.

If $\mathrm{M}>1$ this interval ends when voltage $\mathrm{u}_{\mathrm{Cr}}$ reaches zero, while if $M<1 T_{d}$ is chosen to be one half of the resonant period so as to turn the switch on always at the minimum value of the voltage across it, as shown in Fig. $2 b$ :

$$
\begin{aligned}
& \mathrm{T}_{\mathrm{d}}= \begin{cases}\frac{1}{\omega_{\mathrm{R}}} \cos ^{-1}\left(-\frac{1}{\mathrm{M}}\right) & \text { if } \quad \mathrm{M}>1 \\
\frac{\pi}{\omega_{\mathrm{R}}} & \text { if } \quad \mathrm{M}<1\end{cases} \\
& \mathrm{i}_{\mu}\left(\mathrm{T}_{\mathrm{d}}\right)=\mathrm{I}_{\mu 0}= \\
& =\left\{\begin{array}{lll}
-\frac{\mathrm{U}_{\text {op }}}{\mathrm{Z}_{\mathrm{R}}} \sqrt{1-\left(\frac{1}{M}\right)^{2}} & \text { if } & \mathrm{M}>1 \\
0 & \text { if } & \mathrm{M}<1
\end{array}\right.
\end{aligned}
$$

a)

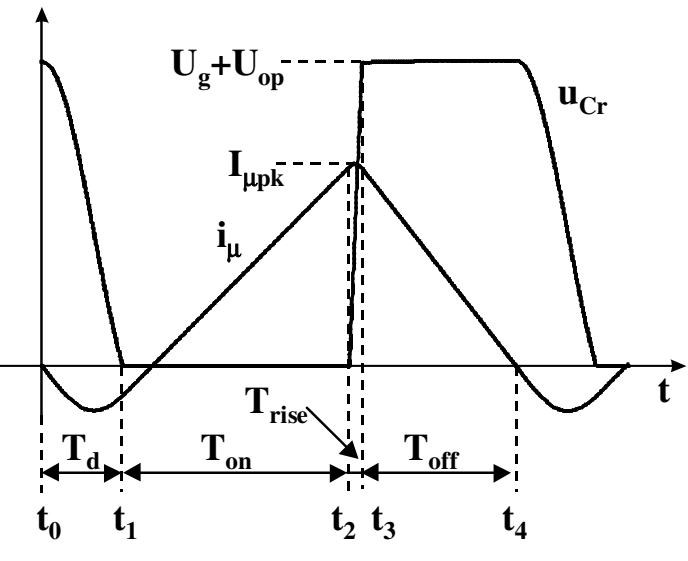

b)

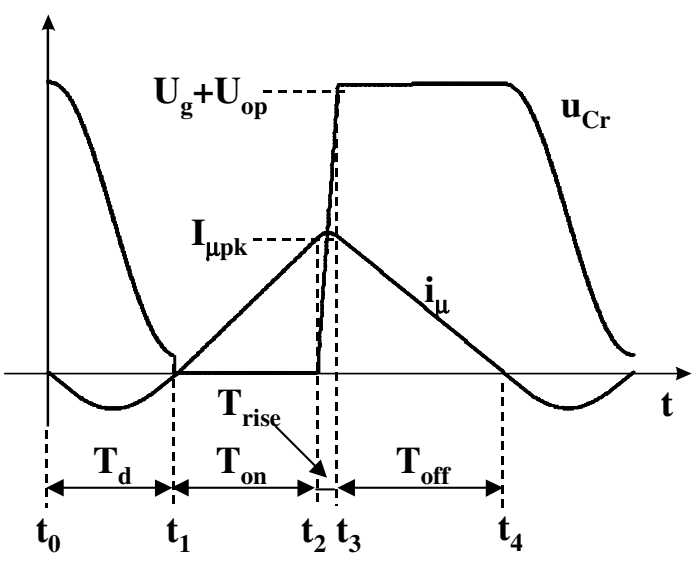

Fig. 2 - Magnetizing current $i_{\mu}$ and resonant capacitor voltage $u_{C r}$ waveforms in a switching period. a) case $\mathrm{M}>1$; b) case $\mathrm{M}<1$

$\mathrm{u}_{\mathrm{Cr}}\left(\mathrm{T}_{\mathrm{d}}\right)=\left\{\begin{array}{lll}0 & \text { if } & \mathrm{M}>1 \\ \mathrm{U}_{\mathrm{g}}-\mathrm{U}_{\mathrm{op}} & \text { if } & \mathrm{M}<1\end{array}\right.$

\section{B. Interval $T_{o n}=t_{2}-t_{1}$.}

The second interval $\left(T_{\text {on }}=t_{2}-t_{1}\right)$ corresponds to the normal charging phase (see Fig. 1c) in which the magnetizing current $i_{\mu}$ increases linearly starting from an initial value which is zero only in the case $\mathrm{M}<1$ and if the switch is turned on at the valley point of voltage $\mathrm{u}_{\mathrm{Cr}}$ (this is the case of Fig. 2b). In the general case we can write:

$\mathrm{i}_{\mu}(\mathrm{t})=\mathrm{I}_{\mu 0}+\frac{\mathrm{U}_{\mathrm{g}}}{\mathrm{L}_{\mu}} \mathrm{t}$

At the end of the switch on-time, the magnetizing current reaches its maximum value (indeed, its maximum occurs during the next resonant period but it differs only slightly from this value):

$$
\mathrm{i}_{\mu}\left(\mathrm{T}_{\mathrm{on}}\right)=\mathrm{I}_{\mu \mathrm{pk}}=\mathrm{I}_{\mu 0}+\frac{\mathrm{U}_{\mathrm{g}}}{\mathrm{L}_{\mu}} \mathrm{T}_{\mathrm{on}} \Rightarrow \mathrm{T}_{\mathrm{on}}=\frac{\mathrm{L}_{\mu}}{\mathrm{U}_{\mathrm{g}}}\left(\mathrm{I}_{\mu \mathrm{pk}}-\mathrm{I}_{\mu 0}\right)
$$

\section{Interval $T_{\text {rise }}=t_{3}-t_{2}$.}

The third interval $\left(T_{\text {rise }}=t_{3}-t_{2}\right)$ is the time between the switch turn off instant and the turn on of the freewheeling diode at the secondary side which occurs when $\mathrm{u}_{\mathrm{Cr}}$ becomes greater than $\mathrm{U}_{\mathrm{g}}+\mathrm{U}_{\mathrm{op}}$. The equivalent circuit during this stage is, again, that shown in Fig. 1b. Due to the high value of the energy stored in the magnetizing inductance, it seems 
reasonable to consider a linear increase of the resonant capacitor voltage at a constant charging current, i.e.:

$$
\begin{aligned}
& \mathrm{u}_{\mathrm{Cr}}(\mathrm{t})=\frac{\mathrm{I}_{\mu \mathrm{pk}}}{\mathrm{C}_{\mathrm{r}}} \mathrm{t} \Rightarrow \mathrm{T}_{\text {rise }}=\frac{\mathrm{C}_{\mathrm{r}}\left(\mathrm{U}_{\mathrm{g}}+\mathrm{U}_{\mathrm{op}}\right)}{\mathrm{I}_{\mu \mathrm{pk}}} \\
& \mathrm{i}_{\mu}(\mathrm{t})=\mathrm{I}_{\mu \mathrm{pk}}
\end{aligned}
$$

However, this approximation can lead to a substantial error in converters designed with a low resonant frequency (for example in order to keep the dv/dt across the switch at turn off below a specified limit), expecially when $M$ becomes lower than one. In these cases an exact analysis must be performed, with the following result:

$\mathrm{u}_{\mathrm{Cr}}(\mathrm{t})=\mathrm{U}_{\mathrm{g}}+\mathrm{Z}_{\mathrm{R}} \hat{\mathrm{I}} \sin \left(\omega_{\mathrm{R}} \mathrm{t}+\alpha\right)$

$\mathrm{i}_{\mu}(\mathrm{t})=\hat{\mathrm{I}} \cos \left(\omega_{\mathrm{R}} \mathrm{t}+\alpha\right)$

where

$$
\begin{aligned}
& \hat{\mathrm{I}}=\sqrt{\mathrm{I}_{\mathrm{Lpk}}^{2}+\left(\frac{\mathrm{U}_{\mathrm{g}}}{\mathrm{Z}_{\mathrm{R}}}\right)^{2}} \\
& \alpha=\operatorname{tg}^{-1}\left(-\frac{\mathrm{U}_{\mathrm{g}}}{\mathrm{Z}_{\mathrm{R}} \mathrm{I}_{\mu \mathrm{pk}}}\right)
\end{aligned}
$$

The interval duration is given by:

$\mathrm{T}_{\text {rise }}=\frac{1}{\omega_{\mathrm{R}}}\left[\sin ^{-1}\left(\frac{\mathrm{U}_{\mathrm{op}}}{\mathrm{Z}_{\mathrm{R}} \hat{\mathrm{I}}}\right)-\alpha\right]$

and the value of the magnetizing current at the end of this interval results:

$$
\mathrm{I}_{\mu \text { off }}=\mathrm{i}_{\mu}\left(\mathrm{T}_{\text {rise }}\right)=\sqrt{\mathrm{I}_{\mu \mathrm{pk}}^{2}+\left(\frac{\mathrm{U}_{\mathrm{op}}}{\mathrm{Z}_{\mathrm{R}}}\right)^{2}\left(\frac{1}{\mathrm{M}^{2}}-1\right)}
$$

Note that, this current is lower than $I_{\mu p k}$ for $M>1$ meaning a reduction of the energy transfered to the output. This fact is in agreement with the situation described in Fig. 2a where a small fraction of the energy store in the magnetizing inductance is, indeed, returned to the input during the first fraction of the switch on-time, where the magnetizing current is negative.

\section{Interval $T_{\text {off }}=t_{4}-t_{3}$.}

During the fourth interval $\left(\mathrm{T}_{\text {off }}=\mathrm{t}_{4}-\mathrm{t}_{3}\right)$ the magnetizing current transfers to the secondary side delivering energy to the load, until it becomes zero, while voltage $\mathrm{u}_{\mathrm{Cr}}$ remains clamped to $\mathrm{U}_{\mathrm{g}}+\mathrm{U}_{\mathrm{op}}$. The magnetizing current is given by (see Fig. 1d):

$\mathrm{i}_{\mu}(\mathrm{t})=\mathrm{I}_{\mu \mathrm{off}}-\frac{\mathrm{U}_{\text {op }}}{\mathrm{L}_{\mu}} \mathrm{t}$

while the duration of such interval results:

$\mathrm{i}_{\mu}\left(\mathrm{T}_{\text {off }}\right)=0 \Rightarrow \mathrm{T}_{\text {off }}=\frac{\mathrm{L}_{\mu} \mathrm{I}_{\mu \text { off }}}{\mathrm{U}_{\text {op }}}$

The total switching period is the sum of all these subintervals, i.e.:

$\mathrm{T}_{\mathrm{S}}=\mathrm{T}_{\mathrm{d}}+\mathrm{T}_{\text {on }}+\mathrm{T}_{\text {rise }}+\mathrm{T}_{\text {off }}$

Neglecting subintervals $T_{\text {rise }}$ and $T_{d}$ allows for $a$ straightforward analysis, since the usual relations of the flyback converter can be used [1]. Unfortunately, when they are not negligible, substantial errors are introduced in the prediction of the switching frequency variation as well as of the component stresses. In the following section, a rigorous analysis is performed with the aim of precisely forecast the converter behavior at different output power and voltage conversion ratios.

\section{DC ANALYSIS}

In order to derive the relation between the voltage conversion ratio and the switching frequency for a given set of the converter parameters, let's start with the determination of the average (in a switching period) current delivered to the load. From Fig. 2 we can write:

$I_{\text {Dp }}=I_{\mu \text { off }} \frac{T_{\text {off }}}{2 T_{S}}$

where $I_{D p}$ is the secondary diode current reported to the primary side. This current equals the average load current, i.e.:

$$
I_{D p}=\frac{U_{o p}}{\eta R_{L}}
$$

where a non unity converter efficiency $\eta$ was assumed. Using (12) and (15) into (14) we obtain:

$$
\frac{\mathrm{L}_{\mu}}{2 \mathrm{~T}_{\mathrm{S}}} \mathrm{I}_{\mu \mathrm{off}}^{2}=\frac{\mathrm{U}_{\mathrm{op}}^{2}}{\eta \mathrm{R}_{\mathrm{L}}}
$$

Now, substituting (2), (5), (9) and (12) into (13) the switching period results:

$$
\begin{aligned}
\mathrm{T}_{\mathrm{S}} & =\left(\mathrm{I}_{\mu \mathrm{pk}}-\mathrm{I}_{\mu 0}\right) \frac{\mathrm{L}_{\mu}}{\mathrm{U}_{\mathrm{op}}} \mathrm{M}+ \\
& +\frac{1}{\omega_{\mathrm{R}}}\left[\sin ^{-1}\left(\frac{\mathrm{U}_{\mathrm{op}}}{\mathrm{Z}_{\mathrm{R}} \hat{\mathrm{I}}}\right)-\alpha\right]+\mathrm{I}_{\mu \mathrm{off}} \frac{\mathrm{L}_{\mu}}{\mathrm{U}_{\mathrm{op}}}+\mathrm{T}_{\mathrm{d}}
\end{aligned}
$$

Now, equations (16) and (17), together with (2), (3) and (8), form a system in the two unknowns $I_{\mu p k}$ and $f_{S}$, which can be solved numerically (a simple MatCad sheet was used to this purpose). The results are shown in Figs. 3a and 3b, which refer to a converter whose specifications and parameters are reported in the experimental result section. Fig. 3a, reports the predicted switching frequency variation as a function of the output power for three different voltage conversion ratios corresponding to a nominal peak input voltage of $311 \mathrm{~V} \pm 20 \%$ (as shown in the experimental result section, the prototype is an off line converter whose input voltage is the rectified line voltage $\mathrm{U}_{\mathrm{IN}}=220 \mathrm{~V}_{\mathrm{rms}} \pm 20 \%$ ). Clearly, as the output power decreases, the switching frequency increases as a consequence of a reduced switch on-time. Fig. 3b, instead, shows the switching frequency variation as a function of the voltage conversion ratio for four different output power levels.

For the purpose of comparison, Fig. 4 shows the difference in the switching frequency prediction as given by three different approaches: the more accurate one (curve a), by neglecting only resonant interval $\mathrm{T}_{\text {rise }}$ (curve $\mathrm{b}$ ) and by neglecting both intervals $T_{\text {rise }}$ and $T_{d}$ (the values corresponding to curve $\mathrm{c}$ are devided by a factor of 3 in order to draw the curves at a reasonable scale): as we can see, just neglecting the short interval $\mathrm{T}_{\text {rise }}$ causes an error in the 
switching frequency prediction which can be as high as $35 \%$ at $20 \mathrm{~W}$. This result is a consequence of the parameter values used in the prototype, where attention was payied in reducing the $\mathrm{dv} / \mathrm{dt}$ across the switch at turn off by lowering the resonant frequency $\omega_{\mathrm{R}}$.

Lastly, Fig. 5 shows the effect of the approximation usually done in the calculation of subinterval $\mathrm{T}_{\text {rise }}$ : curve a) reports the switching frequency prediction given by the approximated equations (6) as compared to the exact analysis: actually, the difference is modest for voltage conversion ratios greater than one and becomes appreciable only when $\mathrm{M}$ is lower than one. In the latter case, at further reduced $M$ values the approximation gives a completely wrong result since the corresponding curve bends until it changes slope, which is clearly an incorrect prediction.

However, it should be mentioned that for converters with significant resonant intervals $T_{d}$ and $T_{\text {rise }}$, particular attention must be payed in order to operate the converter always for $\mathrm{M} \geq 1$ for any input and load condition, since the lost of the soft switching condition at the switch turn on, rapidly increases the switching losses, i.e. from Fig. $2 b$ :

$\mathrm{P}_{\text {disch arge }}=\frac{1}{2} \mathrm{C}_{\mathrm{r}}\left(\mathrm{U}_{\mathrm{g}}-\mathrm{U}_{\mathrm{op}}\right)^{2} \mathrm{f}_{\mathrm{s}}$.

a)

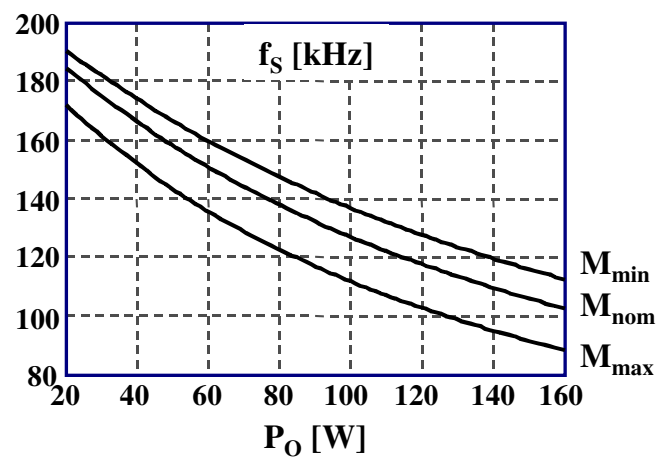

b)

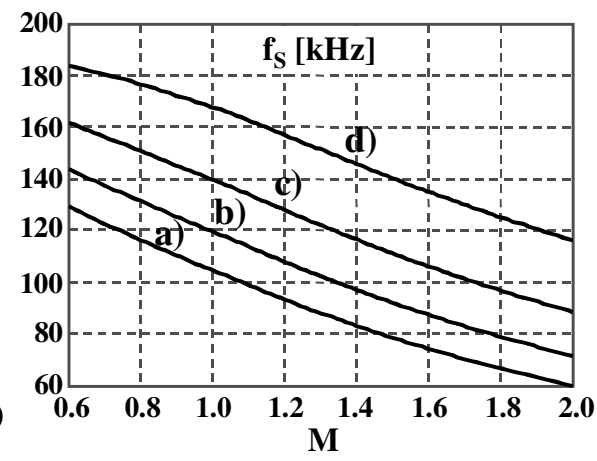

a) $\mathbf{P}_{\text {onom }}$ b) $0.75 P_{\text {onom }}$ c) $0.5 P_{\text {onom }}$ d) $0.25 P_{\text {onom }}$

Fig. 3 - Predicted switching frequency variation: a) as a function of the output power for three different voltage conversion ratios corresponding to a nominal peak input voltage of $311 \mathrm{~V} \pm 20 \%$; b) as a function of the voltage conversion ratio for different output power levels

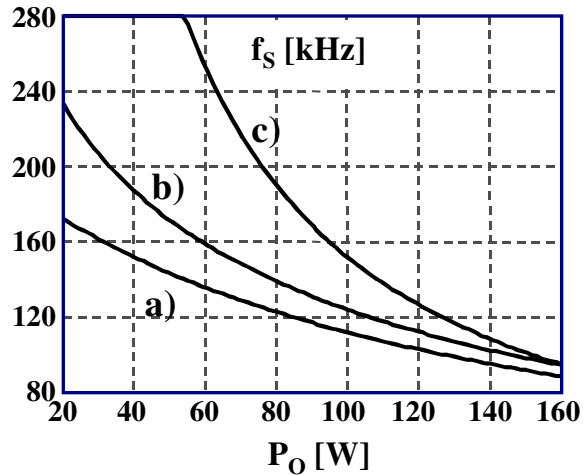

Fig. 4 - Comparison between predicted switching frequency variation as a function of the output power for the maximum voltage conversion ratio. a) accurate analysis; b) by neglecting only resonant interval $\mathrm{T}_{\text {rise }}$; c) by neglecting both intervals $T_{\text {rise }}$ and $T_{d}$ (the values corresponding to curve $c$ are devided by a factor of 3 in order to fit the curve in a reasonable scale)

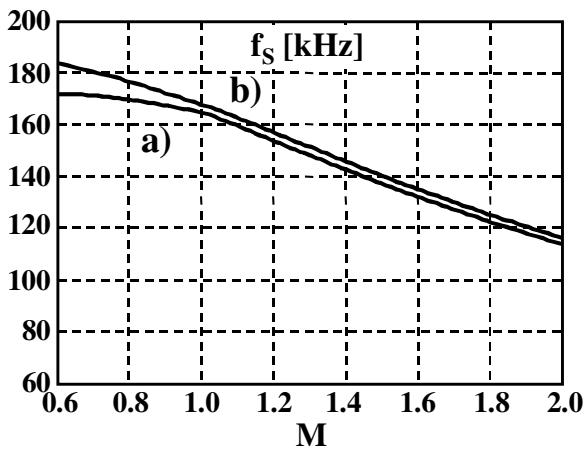

Fig. 5 - Effect of the approximation in the interval $\mathrm{T}_{\text {rise: }}$ a) switching frequency predicted using approximate equations $(6)$; b) switching frequency given by the exact analysis using eqs. (8-10) (correspond to curve d of Fig. 3). $\left(\mathrm{P}_{\mathrm{o}}=0.25 \mathrm{P}_{\text {onom }}\right)$

\section{SMALL-SIGNAL MODEL}

A proper design of the output voltage control loop requires the knowledge of the power stage transfer function. As it is shown in the following section, the IC senses the switch current and compares it with a reference value provided by the external control loop, thus realizing a well known peak current control. Once again, since the converter works at the boundary between the continuous and discontinuous conduction modes, we are tempted to use the usual constant frequency small signal models. However, a dilemma rises: we should use the model for CCM or for DCM operation? Fortunately, the difference is not so high except for the phase behavior at high frequency. However, it is worthy to know the error magnitude we do when neglecting the resonant subintervals. Thus, in this section, a more accurate model is derived based on the real converter waveforms. Since the interest of this converter is in the soft-switching operation, which implies the condition $\mathrm{M} \geq 1$, the approximate equations for the $T_{\text {rise }}$ subinterval were used. The details of such analysis are reported in the Appendix. The result is the simple circuit model shown in Fig. 6 (output section only): from it, the transfer function $G_{p}(s)$ between the control signal $I_{R}$ and the output voltage can be easily found as:

$\mathrm{G}_{\mathrm{p}}(\mathrm{s})=\mathrm{h}_{\mathrm{R}} \frac{\mathrm{R}_{\mathrm{Lp}} / / \mathrm{r}_{\mathrm{o}}}{1+\mathrm{sC}_{\mathrm{Lp}}\left(\mathrm{R}_{\mathrm{Lp}} / / \mathrm{r}_{0}\right)}$ 
where $\mathrm{R}_{\mathrm{Lp}}$ and $\mathrm{C}_{\mathrm{Lp}}$ are the total load resistance and total filter capacitor reported to the primary side and $r_{o}$ is a damping resistance given by the small-signal model.

Fig. 7 shows the comparison between the bode plots of the derived $G_{p}(j \omega)$ (curve a)) and those obtained by using the classical transfer functions of the flyback converter for CCM operation (curve b)) and DCM operation (curve c)): as can be seen the latter predict a much higher static gain as compared with the more accurate one. Note that the error introduced by the DCM transfer function is mainly due to the high error in the switching frequency prediction if the resonant subintervals are neglected. If the correct switching frequency is used in this transfer function, than the error reduces and curve c) moves closer to curve a) but still remaining at a higher gain.

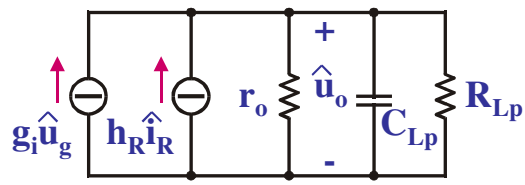

Fig. 6 -Small-signal equivalent model of the flyback converter in the critical conduction mode (output section only)
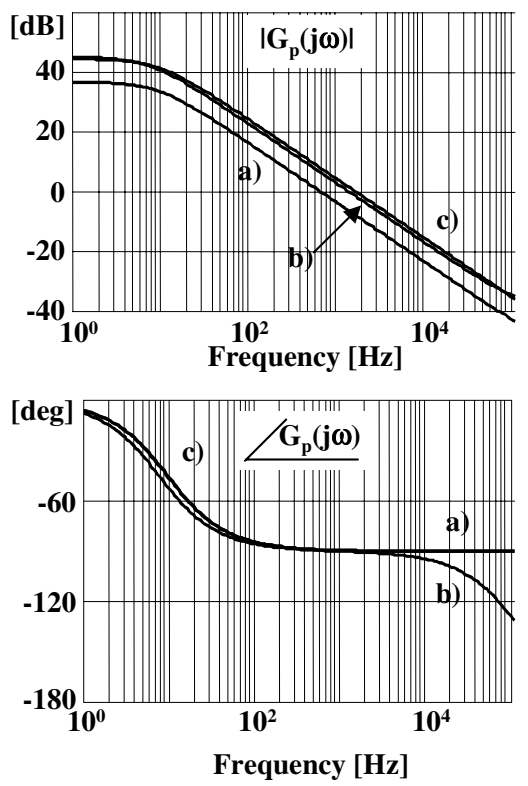

Fig. 7 - Bode diagram of $\left|\mathrm{G}_{\mathrm{p}}(\mathrm{j} \omega)\right|$ and $\angle \mathrm{G}_{\mathrm{p}}(\mathrm{j} \omega)$ for $\mathrm{U}_{\mathrm{g}}=\mathrm{U}_{\mathrm{gmin}}$ and nominal power. a) Accurate small signal model reported in the paper; b) standard small-signal model for CCM operation; c) standard small-signal model for DCM operation

\section{SMARTPOWER IC}

ST Microelectronics has developed a new smartpower IC specifically designed for off-line flyback power supplies in the critical conduction mode [2]. Their new high voltage VIPower M3 technology, monolithically combining an Emitter Switching Bipolar-MOSFET Power Stage and a flexible BCD (Bipolar - CMOS - DMOS) control part, is ideally suited to develop state-of-the-art off-line SMPS in the 100 to 250 Watts output power range [3-5]. This level of power covers numerous applications, among which are power supplies for Monitors, TVCs and Desktop PCs. The block diagram of such IC is reported in Fig. 8 together with the scheme showing its application to an off-line multioutput flyback converter. For a detailed description of the IC internal blocks refers to [2]; here, it is worthy only to mention the presence of a high voltage comparator (H.V.Comp) which directly senses the collector voltage of the power device (which can reach voltages in excess of 900V) in order to exactly synchronize its turn on with the zero crossing of voltage $\mathrm{u}_{\mathrm{Cr}}$, if the converter is operating with $\mathrm{M}>1$. An alternative switch on trigger is provided by the low-voltage comparator (Comp1) by sensing the auxiliary winding voltage in the case of $M<1$ (in this case the converter behaves as shown in Fig. 2b). Lastly, note that an inner peak current control is provided by the internal current sense resistor $R_{s}$ and associated comparator (Current Limiter). The internal Error Amplifier, which is normally disabled in the presence of an external voltage control loop, allows for an alternative control loop through the supply voltage when the latter is provided by an auxiliary transformer winding, as shown in Fig. 8.
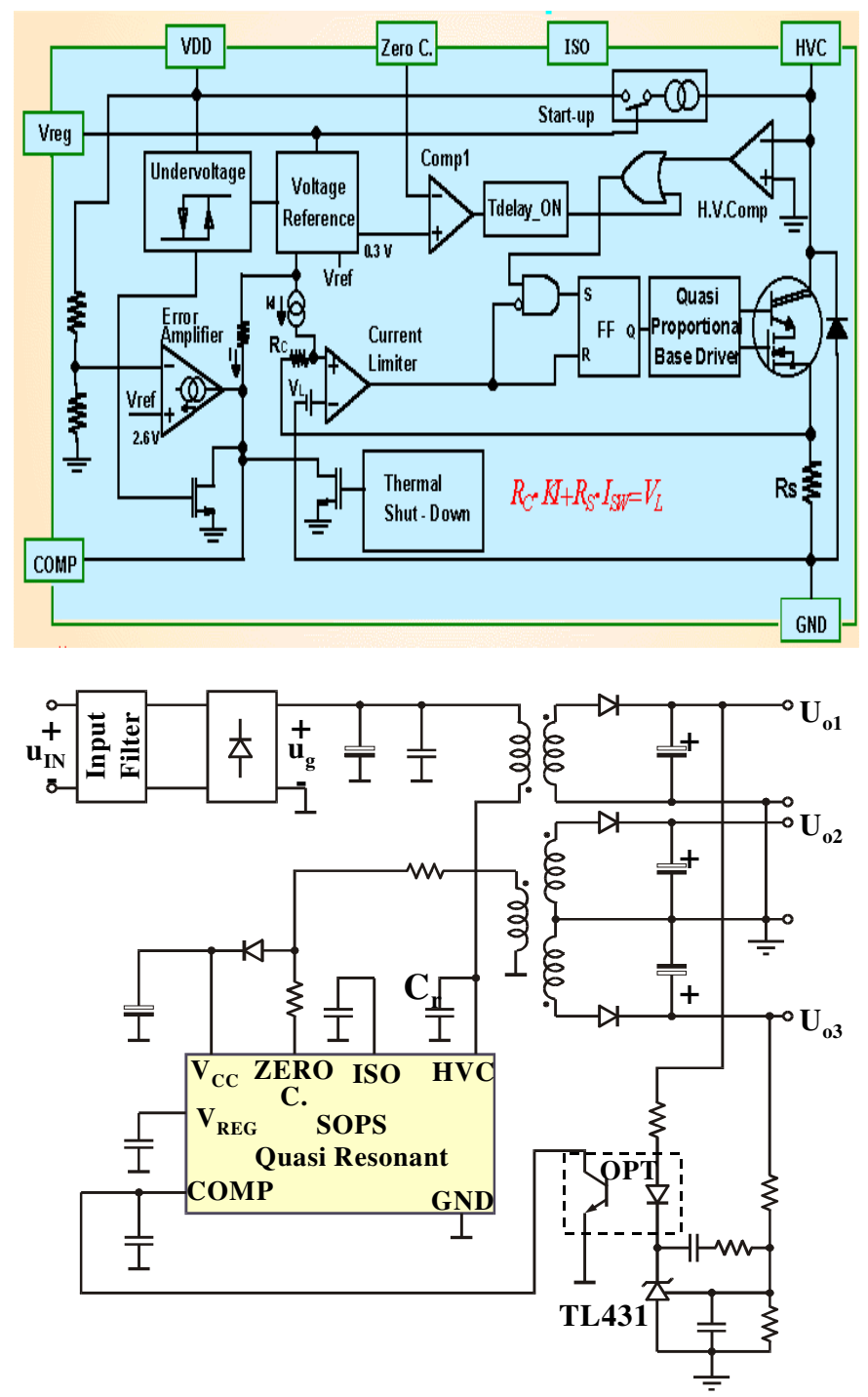

Fig. 8 - Block diagram of the smartpower IC and its application to a multioutput flyback power supply 


\section{EXPERIMENTAL RESULTS}

A multioutput flyback prototype, whose scheme is shown in Fig. 8, has been built and is currently under test. Its parameters are the following:

\begin{tabular}{|l|l|l|}
\hline $\mathrm{U}_{\mathrm{IN}}=220 \mathrm{Vrms} \pm 20 \%$ & $\mathrm{~L}_{\mu}=307 \mu \mathrm{H}$ & $\mathrm{C}_{\mathrm{r}}=2 \mathrm{nF}$ \\
\hline $\mathrm{P}_{\mathrm{oN}}=160 \mathrm{~W}$ & $\eta_{\mathrm{est}}=0.8$ & $\mathrm{C}_{\mathrm{Lp}}=51 \mu \mathrm{F}$ \\
\hline $\mathrm{U}_{\mathrm{o} 1}=30 \mathrm{~V}$ & $\mathrm{U}_{\mathrm{o} 2}=15 \mathrm{~V}$ & $\mathrm{U}_{\mathrm{o} 3}=135 \mathrm{~V}$ \\
\hline $\mathrm{U}_{\mathrm{o} 3 \mathrm{P}}=322 \mathrm{~V}$ & & \\
\hline
\end{tabular}

where $\eta_{\text {est }}$ is the estimated overall efficiency and $U_{\mathrm{o} 3 \mathrm{P}}$ is the controlled output voltage reflected to the primary side. These values are typical for TVC applications. The switching frequency variation, as a function of the total output power, for $\mathrm{U}_{\mathrm{IN}}=176 \mathrm{~V}_{\mathrm{rms}}$ is reported in Fig. 9 together with the values predicted by the proposed analysis: note that these calculated values differ slightly from the corresponding values of the curve in Fig. 3a) because the measured input voltage $\mathrm{U}_{\mathrm{g}}$ was used in the algorithm instead of a constant one (being $\mathrm{U}_{\mathrm{g}}$ derived from rectification of the line voltage its actual mean value depends on the output power).

The voltage across the resonant capacitor $\mathrm{u}_{\mathrm{Cr}}$ (which is also the voltage across the power switch) at nominal output power and minimum input voltage is shown in Fig. 10: except for the parasitic oscillations at the top of the waveform caused by the transformer leakage inductance, it is very similar to the simulated one shown in Fig. 2a.

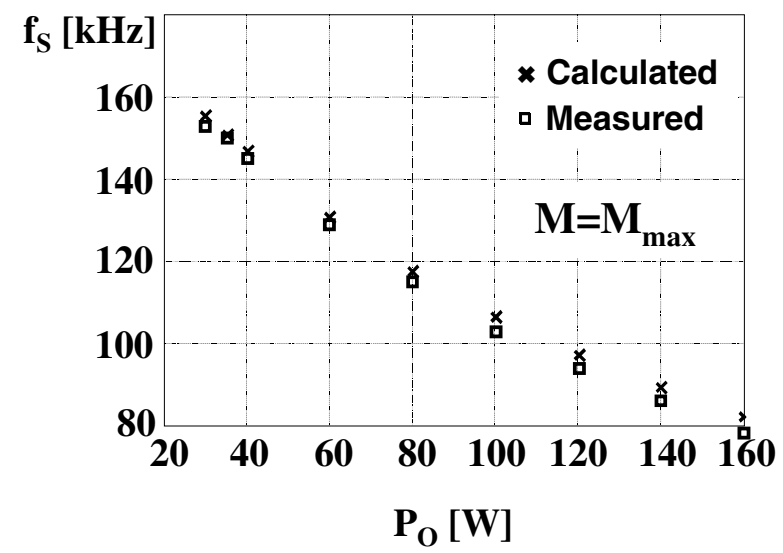

Fig. 9 - Comparison between predicted ( $\boldsymbol{\varkappa}$ ) and measured (ㅁ) switching frequency as a function of output power for $\mathrm{M}=\mathrm{M}_{\max }$

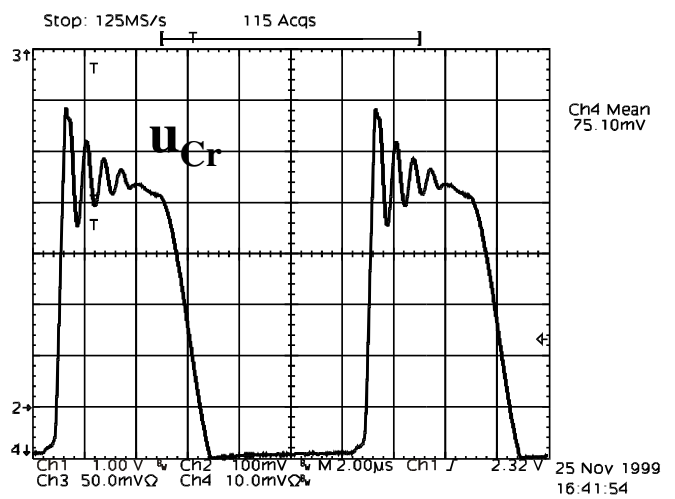

Fig. 10 - Resonant capacitor voltage $\mathrm{u}_{\mathrm{Cr}}$ at minimum input voltage and nominal output power

\section{CONCLUSIONS}

In this paper, the critical conduction operating mode of a DC-DC flyback SMPS was re-examined: the switching frequency variation as a function of the voltage conversion ratio and of the load power was accurately predicted taking into account the resonant subintervals.

A suitable small-signal model was presented and its differences with the standard approaches were highlighted.

The theoretical forecasts were verified by means of a multi-output flyback prototype built using a new smartpower IC developed by ST Microelectronics in VIPower ${ }^{\circledR}$ M3 technology.

\section{REFERENCES}

1. P. Lidak, Critical Conduction Mode Flyback Switching Power Supply using the MC33364, Motorola Semiconductor Application Note AN1594.

2. A. Russo, D. Tagliavia, S. Spampinato, "Zero Voltage Synchronous Quasi Resonant Flyback Converter in VIPower M3 Technology," Proc. of PCIM, 1999, pp.273-279.

3. S. Sueri, "VIPower M3: A New Smart Technology for High Power, High Speed Applications," Proc of PCIM, 1997, pp.19-27.

4. M. Melito G. Belverde, A. Galluzzo, S. Palara, "BipolarMOS Monolithic Cascode Switch in VIPower Technology," IEEE IAS Anual Conference Proc., Denver, 1994, pp.1322-1325.

5. S. Musumeci, G. Oriti, A. Raciti, A. Testa, M. Melito, A. Galluzzo, "Hard and Soft Switching Bahavior of a New Bipolar cascode Monolithic Switch," EPE Conf. Proc., Sevilla, 1995, pp.2.262-2.267. 


\section{APPENDIX}

Determination of the small-signal model coefficients.

Let us start with the magnetizing current peak as imposed by the external reference current $\mathrm{I}_{\mathrm{R}}$ :

$\mathrm{I}_{\mu \mathrm{pk}}=\mathrm{I}_{\mathrm{R}}+\frac{\mathrm{U}_{\mathrm{g}}}{\mathrm{L}_{\mu}} \mathrm{T}_{\mathrm{STO}}$

where $\mathrm{T}_{\mathrm{STO}}$ is the emitter switching storage time. It seems reasonable to assume a linear dependance of such interval on the peak current at turn off, i.e.:

$\mathrm{T}_{\mathrm{STO}}=\gamma \mathrm{I}_{\mathrm{R}}$

$\mathrm{I}_{\mu \mathrm{pk}}=\mathrm{I}_{\mathrm{R}}\left(1+\frac{\mathrm{U}_{\mathrm{g}}}{\mathrm{L}_{\mu}} \gamma\right)=\beta \mathrm{I}_{\mathrm{R}}$

The average current delivered to the output coincides with the diode current, i.e.:

$$
\mathrm{I}_{\mathrm{D}}=\mathrm{I}_{\mathrm{op}}=\mathrm{I}_{\mu \mathrm{pk}} \frac{\mathrm{d}^{\prime}}{2}
$$

where d' is the relative time during which the diode current is greater than zero. Note that the approximation $\mathrm{I}_{\mu \mathrm{pk}} \approx \mathrm{I}_{\mu \mathrm{off}}$ was used.

$\mathrm{I}_{\mu \mathrm{pk}}=\frac{\mathrm{U}_{\mathrm{op}}}{\mathrm{L}_{\mu}} \mathrm{d}^{\prime} \mathrm{T}_{\mathrm{S}} \Rightarrow \mathrm{d}^{\prime}=\mathrm{I}_{\mu \mathrm{pk}} \frac{\mathrm{L}_{\mu} \mathrm{f}_{\mathrm{S}}}{\mathrm{U}_{\mathrm{op}}}$

Substituting (A.3) and (A.5) into (A.4) we obtain:

$I_{D}=I_{\mu p k}^{2} \frac{L_{\mu}}{2 U_{o p} T_{S}}=\beta^{2} I_{R}^{2} \frac{L_{\mu}}{2 U_{o p} T_{S}}=f\left(U_{g}, I_{R}, U_{o p}\right)$

A suitable small-signal model is derived using the first order taylor series of (A.6):

$\hat{i}_{D}=\frac{\partial I_{D}}{\partial U_{g}} \hat{u}_{g}+\frac{\partial I_{D}}{\partial I_{R}} \hat{i}_{R}+\frac{\partial I_{D}}{\partial U_{o p}} \hat{u}_{o p}=g_{i} \hat{u}_{g}+h_{R} \hat{i}_{R}-g_{o} \hat{u}_{o p}$

where the coefficients $\mathrm{g}_{\mathrm{i}}, \mathrm{h}_{\mathrm{R}}, \mathrm{g}_{\mathrm{o}}$ are given by:

$$
\begin{aligned}
& \mathrm{g}_{\mathrm{i}}=\frac{\partial \mathrm{I}_{\mathrm{D}}}{\partial \mathrm{U}_{\mathrm{g}}}=-\beta^{2} \mathrm{I}_{\mathrm{R}}^{2} \frac{\mathrm{L}_{\mu}}{2 \mathrm{U}_{\mathrm{op}} \mathrm{T}_{\mathrm{S}}^{2}} \frac{\partial \mathrm{T}_{\mathrm{S}}}{\partial \mathrm{U}_{\mathrm{g}}} \\
& \mathrm{h}_{\mathrm{R}}=\frac{\partial \mathrm{I}_{\mathrm{D}}}{\partial \mathrm{I}_{\mathrm{R}}}=\beta^{2} \frac{\mathrm{L}_{\mu}}{2 \mathrm{U}_{\mathrm{op}} \mathrm{T}_{\mathrm{S}}^{2}}\left(2 \mathrm{I}_{\mathrm{R}} \mathrm{T}_{\mathrm{S}}-\mathrm{I}_{\mathrm{R}}^{2} \frac{\partial \mathrm{T}_{\mathrm{S}}}{\partial \mathrm{I}_{\mathrm{R}}}\right) \\
& \mathrm{g}_{\mathrm{o}}=-\frac{\partial \mathrm{I}_{\mathrm{D}}}{\partial \mathrm{U}_{\mathrm{op}}}=\frac{\beta^{2} \mathrm{I}_{\mathrm{R}}^{2} \mathrm{~L}_{\mu}}{2 \mathrm{U}_{\mathrm{op}}^{2} \mathrm{~T}_{\mathrm{S}}^{2}}\left(\mathrm{~T}_{\mathrm{S}}+\mathrm{U}_{\mathrm{op}} \frac{\partial \mathrm{T}_{\mathrm{S}}}{\partial \mathrm{U}_{\mathrm{op}}}\right)
\end{aligned}
$$

As we can see the partial derivatives of $\mathrm{T}_{\mathrm{S}}$ are involved in the above expressions. In order to calculate them, we substitute (A.3) into (17) were the approximated equations (6) are used, thus obtaining:

$\mathrm{T}_{\mathrm{S}}=\left(\beta \mathrm{I}_{\mathrm{R}}-\mathrm{I}_{\mu 0}\right) \frac{\mathrm{L}_{\mu}}{\mathrm{U}_{\mathrm{g}}}+\left(\mathrm{U}_{\mathrm{g}}+\mathrm{U}_{\mathrm{op}}\right) \frac{\mathrm{C}_{\mathrm{R}}}{\beta \mathrm{I}_{\mathrm{R}}}+\beta \mathrm{I}_{\mathrm{R}} \frac{\mathrm{L}_{\mu}}{\mathrm{U}_{\mathrm{op}}}+\mathrm{T}_{\mathrm{d}}$

Attention must be paided by remembering that both $\mathrm{I}_{\mu 0}$ and $T_{d}$ are functions of $U_{g}$ and $U_{o p}$ in the case of $M>1$.

The desired partial derivatives are:

$$
\begin{aligned}
& \frac{\partial \mathrm{T}_{\mathrm{S}}}{\partial \mathrm{U}_{\mathrm{g}}}=-\left(\beta \mathrm{I}_{\mathrm{R}}-\mathrm{I}_{\mu 0}\right) \frac{\mathrm{L}_{\mu}}{\mathrm{U}_{\mathrm{g}}^{2}}+\frac{\mathrm{C}_{\mathrm{R}}}{\beta \mathrm{I}_{\mathrm{R}}} \\
& \frac{\partial \mathrm{T}_{\mathrm{S}}}{\partial \mathrm{U}_{\mathrm{op}}}=-\beta \mathrm{I}_{\mathrm{R}} \frac{\mathrm{L}_{\mu}}{\mathrm{U}_{\mathrm{op}}^{2}}+\frac{\mathrm{C}_{\mathrm{R}}}{\beta \mathrm{I}_{\mathrm{R}}}+\left[\frac{\partial \mathrm{T}_{\mathrm{d}}}{\partial \mathrm{U}_{\mathrm{op}}}-\frac{\mathrm{L}_{\mu}}{\mathrm{U}_{\mathrm{g}}} \frac{\partial \mathrm{I}_{\mu 0}}{\partial \mathrm{U}_{\mathrm{op}}}\right] \\
& \frac{\partial \mathrm{T}_{\mathrm{S}}}{\partial \mathrm{I}_{\mathrm{R}}}=\beta \mathrm{L}_{\mu}\left(\frac{1}{\mathrm{U}_{\mathrm{g}}}+\frac{1}{\mathrm{U}_{\mathrm{op}}}\right)-\frac{\mathrm{C}_{\mathrm{R}}}{\beta \mathrm{I}_{\mathrm{R}}^{2}}\left(\mathrm{U}_{\mathrm{g}}+\mathrm{U}_{\mathrm{op}}\right)
\end{aligned}
$$

where the term inside the square brackets in (A.13) is non zero only for $M>1$. From (2) and (3) we can write:

$\frac{\partial \mathrm{T}_{\mathrm{S}}}{\partial \mathrm{U}_{\mathrm{op}}}=-\beta \mathrm{I}_{\mathrm{R}} \frac{\mathrm{L}_{\mu}}{\mathrm{U}_{\mathrm{op}}^{2}}+\frac{\mathrm{C}_{\mathrm{R}}}{\beta \mathrm{I}_{\mathrm{R}}}+\left[\frac{1}{\omega_{\mathrm{R}} \mathrm{U}_{\mathrm{g}}} \sqrt{1-\left(\frac{\mathrm{U}_{\mathrm{g}}}{\mathrm{U}_{\mathrm{op}}}\right)^{2}}\right] \cdot \mathrm{x}$

where $\mathrm{x}$ is a logic variable given by:

$x=\left\{\begin{array}{lll}1 & \text { for } & M>1 \\ 0 & \text { for } & M<1\end{array}\right.$

Substituting (A.12-15) into (A.8-10) we obtain:

$$
\begin{aligned}
& g_{\mathrm{i}}=\frac{\beta^{2} \mathrm{I}_{\mathrm{R}}^{2} \mathrm{~L}_{\mu}}{2 \mathrm{U}_{\mathrm{op}} \mathrm{T}_{\mathrm{S}}^{2}}\left(\left(\beta \mathrm{I}_{\mathrm{R}}-\mathrm{I}_{\mu 0}\right) \frac{\mathrm{L}_{\mu}}{\mathrm{U}_{\mathrm{g}}^{2}}-\frac{\mathrm{C}_{\mathrm{R}}}{\beta \mathrm{I}_{\mathrm{R}}}\right) \\
& \mathrm{h}_{\mathrm{R}}=\beta^{2} \frac{\mathrm{I}_{\mathrm{R}} \mathrm{L}_{\mu}}{2 \mathrm{U}_{\mathrm{op}} \mathrm{T}_{\mathrm{S}}}\left(2-\frac{\mathrm{U}_{\mathrm{g}}+\mathrm{U}_{\mathrm{op}}}{\mathrm{T}_{\mathrm{S}}}\left(\frac{\beta \mathrm{I}_{\mathrm{R}} \mathrm{L}_{\mu}}{\mathrm{U}_{\mathrm{g}} \mathrm{U}_{\mathrm{op}}}-\frac{\mathrm{C}_{\mathrm{R}}}{\beta \mathrm{I}_{\mathrm{R}}}\right)\right)
\end{aligned}
$$

$$
\begin{aligned}
& \mathrm{g}_{\mathrm{o}}=\frac{\mathrm{L}_{\mu}}{2}\left(\frac{\beta \mathrm{I}_{\mathrm{R}}}{\mathrm{U}_{\mathrm{op}} \mathrm{T}_{\mathrm{S}}}\right)^{2} \cdot \\
& \cdot\left(\mathrm{T}_{\mathrm{S}}+\mathrm{U}_{\mathrm{op}} \frac{\mathrm{C}_{\mathrm{R}}}{\beta \mathrm{I}_{\mathrm{R}}}-\beta \mathrm{I}_{\mathrm{R}} \frac{\mathrm{L}_{\mu}}{\mathrm{U}_{\mathrm{op}}}+\left[\frac{\mathrm{U}_{\mathrm{op}}}{\omega_{\mathrm{R}} \mathrm{U}_{\mathrm{g}}} \sqrt{1-\left(\frac{\mathrm{U}_{\mathrm{g}}}{\mathrm{U}_{\mathrm{op}}}\right)^{2}}\right] \cdot \mathrm{x}\right)
\end{aligned}
$$

